\title{
Reading for fun is a novel idea
}

By Gary Mayhood and Karen Stabler

\section{Faculty book reviews encourage reading}

$\mathbf{N}$ ight over Water, Cold Sassy Tree, Confederacy of Dunces, Bonfire of the Vanities, The Negotiator, and Lonesome Dove are novels selected by the New Mexico State University faculty for the library booklet "In Celebration of Reading." For the past three spring semesters the Library Publications Committee has compiled a booklet of reviews of novels written by our faculty to promote summer reading. Entertaining, insightful, and significant books are the criteria for selection.

\section{Publishing a review booklet}

There are four purposes for the publication.

1) To encourage students to a lifelong reading program that continues after formal university training. This is especially important to our ethnically diverse student population. The university has a student body of over 15,000 of which 80 percent are undergraduates. It is more ethnically diverse than most universities as 68 percent are Anglo, 27 percent are Hispanic, three percent are Native-American, and two percent represent other groups. Also, two-thirds of the student body are from New Mexico, where a significant proportion of the population of this predominantly rural state still does not have access to library service.

2) To stimulate students' recreational reading.

3) To allow students to know faculty on a more personal basis by seeing what faculty like to read outside their field of study.

4) To promote good public relations between the town and university by having fac- ulty recommend good books, as an alternative to other activities like sports, music, or theater.

The Library Publications Committee, composed of seven members of the library faculty and staff, oversees and coordinates all publications produced for our users. The committee begins the process of organizing "In Celebration of Reading" in late fall. The members meet to decide on a theme for choosing reviewers, i.e., faculty-of-the-year award recipients or teaching faculty who serve on library committees. The committee then creates a list of likely faculty willing to write reviews, and the names are divided between the committee members to make an initial contact by telephone. This call consists of a description of the project, a request for the title of the book to be reviewed by mid-February, and the completed review by mid-March. We then send a follow-up letter and make gentle reminder telephone calls as deadlines approach.

Once the reviews are in hand, we use desktop publishing to produce a booklet using IBM, Macintosh IIci, and an Abaton Scanner 300/s hardware; and WordPerfect, Microsoft Word, PageMaker, Adobe Illustrator, and OmniPage software. A committee member usually volunteers to photograph each of the reviewers in a personalized setting. Bid estimates are then obtained from local printers. Because our booklet is camera-ready our costs for printing 1,500 of them - containing approximately seven reviews on separate pages with an introductory page and cover-have been under $\$ 200$.

\section{Publicizing summer reading}

Once the booklets are printed, the committee disseminates and publicizes the summer read-

(Novel idea cont. on page 73) 
needed to learn how to access applications from the server and store files on the network drives. For this exercise a document was created and stored on the shared network drive which is accessible to all library staff. The trainees were given step-by-step instructions for loading the network copy of WordPerfect, opening the document, and adding information to it.

Exercise \#7: External communication. Many academic librarians now have access to the Internet through their campus networks, and have discovered the ease and convenience of communicating electronically with colleagues. This exercise taught trainees how to send an Internet message. A former employee at another institution agreed to be the recipient of their practice messages. In addition, since I subscribed to several library-oriented lists on the Internet, I began forwarding relevant messages to appropriate staff so they would become aware of the usefulness of the national network for exchanging information and ideas. ${ }^{3}$

Exercise \#8: Modem communication. Librarians have preceded most other microcomputer users in realizing the power of the modem because online searching of external databases has long been a standard service at most academic libraries. With this exercise trainees learned how to access the university network by modem. They were introduced to the basic Unix commands required to read their mail and send a message. They also saw how our library catalog was used by dial-in patrons.

\section{What we learned}

People learn at different rates and have different tolerances for the need to teach themselves through experimentation. The staff behaved like a typical class of students: some did the exercises regularly, others delayed work and then did several at once. Individual tutoring was available on request, but questions during the training exercises were few. Most users waited until they had a specific project or need before asking for help.

No one will use the network to its fullest. The manuals which document the network and all its applications fill many shelves, but most users discover the techniques that make their lives easier and stick with them. With encouragement, adventuresome users continue to explore new ways to use the network. It is difficult for people to check their mail each day and make full use of the network when each person does not have a microcomputer on her or his desk. But now it is reassuring to know that the draft of the library newsletter, the dBase file of the gift books, the spreadsheets of cataloging statistics, and other important files reside on the secure network drive.

The learn-the-network-by-using-the-network-approach has been successful. Staff have a common set of experiences that makes discussing individual problems easier. The value of continuing education through individualized instruction cannot be denied, and the network exercises have simplified our effort. As a person who finds computers quite interesting and enjoys discovering new ways to use the computer to do old tasks, this trainer took delight as staff interest in the network began to grow. And as staff members become more confident, they become motivated to make their own discoveries.

\section{Notes}

'The campus network environment is more fully described in Shyamaia Reddy, "School maze, networking a geographically diverse university campus," LAN 5 (May 1990): 114-22.

2PC-NFS provides a user-friendly mail application called LifeLine Mail.

${ }^{3}$ For a useful overview of the networks see: Caroline R. Arms, "Using the national networks: BITNET and the Internet," Online 14 (September 1990): 24-29.

(Novel idea cont. from page 69)

ing program during National Library Week in April. There is a display in the lobby of the library consisting of the books reviewed and photographs of the reviewers. The booklets are distributed at various points within the library, in university colleges, the student union, and the branch campuses. To improve town and university relations, we also distribute these booklets to the public library, civic organizations, and the cultural center. Always eager to offer community service spots, local radio and television stations air interviews and promote our summer reading program.

In this age of computer technology, libraries are more than just bytes of information flowing through a tangled web of networks. There are shelves of books that provide ideas, thoughts, and pleasure. A positive indicator for the program is the increase in circulation statistics for the books reviewed. People come to the library and ask for the booklet and the faculty are very supportive and positive about the program. 